\title{
Synthesis and Properties of Lead Magnesium Niobate Zirconate
} Relaxor Materials

\author{
Arian Nijmeijer and Henk Kruidhof \\ Laboratory for Inorganic Materials Science, Department of Chemical Technology, University of Twente, \\ 7500 AE Enschede, The Netherlands
}

Detlev Hennings*

Philips Forschungslabor, 52021 Aachen, Germany

Two materials were prepared with composition $\mathrm{PbMg}_{0,3}$ $\mathrm{Nb}_{0.6} \mathrm{Zr}_{0.1} \mathrm{O}_{3}(\mathrm{PMNZ/10})$ and $\mathrm{PbMg}_{0.32} \mathrm{Nb}_{0.65} \mathrm{Zr}_{0.03} \mathrm{O}_{3}$ (PMNZ/3). Slight modifications in lead oxide content of these materials were made to study its influence on the sintering properties. The stoichiometric PMNZ/3 gave the best results. It has a sintering temperature as low as $900^{\circ} \mathrm{C}$ and a relative dielectric constant of 10000 at room temperature.

\section{Introduction}

$\mathrm{L}$ EAD-BASED perovskite materials are very promising for use in multilayer ceramic capacitors (MLCCs). These materials may have advantages over the conventional materials such as barium titanate. They exhibit a very broad dielectric maximum, due to the diffuse phase transition. This is related to the existence of ferroelectric domains far above the Curie temperature, described, for example, by Stenger and Burggraaf. ${ }^{1-3}$

An additional advantage is the low sintering temperature around $950^{\circ} \mathrm{C}$. This enables the use of low-cost electrodes, for instance silver-based. ${ }^{4}$ Conventional barium titanate has a sintering temperature of at least $1100^{\circ} \mathrm{C}$, which makes it necessary to use expensive Pd-based electrodes. The cost of the palladium electrode material is very important because it constitutes $30-60 \%$ of the total price of an MLCC. ${ }^{5}$

Lead-based relaxor materials have a high dielectric maximum. For titanium-doped lead magnesium niobate, $\mathrm{PbMg}_{x} \mathrm{Nb}_{2 x} \mathrm{Ti}_{1-3 x} \mathrm{O}_{3}$ (PMNT), a dielectric maximum has been reported $^{6,7}$ of $K=50000$. A serious drawback of lead-based relaxor materials is the inherent use of lead, which imposes an environmental problem during synthesis of the capacitor as well as on waste disposal or recycling. The first lead-based relaxors, such as lead magnesium niobate $\left(\mathrm{PbMg}_{1 / 3} \mathrm{Nb}_{2 / 3} \mathrm{O}_{3}\right.$ : PMN), were synthesized by Smolenskii and Agranovskaya. The temperature characteristics of these materials, however, were rather poor. Over the years a lot of research has been performed on relaxor materials, and in the meantime $\mathrm{Y}^{\dagger} \mathrm{V}^{\dagger}$ temperature characteristics set by the Electronic Industries Association (EIA) have been met (see, for example, Ref. 4). Silver doping can have a positive effect on these temperature characteristics as shown by Mahler ${ }^{9}$ and Sato et al. ${ }^{10}$ The objective of this research was to find a new material with a low sintering

G. H. Maher-contributing editor temperature which exhibits a broad Curie region combined with a high dielectric constant.

\section{Experimental Procedure}

The main problem encountered in synthesis of lead magnesium niobate ceramics is the occurrence of a stable pyrochlore phase, as described by Shrout and Swartz. ${ }^{11}$ This pyrochlore phase is detrimental for the dielectric properties of the material. Swartz et al. ${ }^{12}$ avoided the formation of this phase by first reacting magnesium oxide and niobium oxide to form pyrochlore magnesium niobate or columbite. This magnesium niobate was further reacted to form perovskite lead magnesium niobate.

In this work essentially the same columbite method was used. Commercially available magnesium niobate ${ }^{\ddagger}$ with a grain size less than $75 \mu \mathrm{m}$ was mixed with yellow $\mathrm{PbO}^{\S}$ with a grain size less than $10 \mu \mathrm{m}$ zirconium dioxide ${ }^{\ddagger}$ and magnesium oxide. ${ }^{\text {II }}$ An extra addition of $5 \mathrm{~mol} \% \mathrm{MgO}$ was applied to avoid a pyrochlore second phase. The mixture was homogenized for $16 \mathrm{~h}$ in a planetary mill using $50 \mathrm{~mL}$ of 2-propanol ${ }^{\S}$ and 10 calcium-stabilized zirconia balls with a diameter of $10 \mathrm{~mm}$ and 1 calcium-stabilized zirconia ball with a diameter of $20 \mathrm{~mm}$ per $3 / 8$ mol material. All materials used were $>99.9 \%$ purity. The resulting slurry was dried in a stove at $100^{\circ} \mathrm{C}$ for $2 \mathrm{~h}$ and calcined at five different temperatures in the range from $650^{\circ}$ to $900^{\circ} \mathrm{C}$. X-ray diffraction analysis (Philips PW1710) was performed to choose the optimum calcination temperature, with respect to the occurrence of second phases. The calcined powder was sintered at temperatures varying between $850^{\circ}$ and $1000^{\circ} \mathrm{C}$ for $10 \mathrm{~h}$ in a lead atmosphere to avoid evaporation. The samples were therefore placed in a platinum cup filled with lead zirconate $\left(\mathrm{PbZrO}_{3}\right)$.

After synthesis the density of the materials was measured by immersing the sample in mercury. Composition analysis was performed using X-ray fluorescence (XRF, Philips PW 1480) and atomic absorption spectroscopy (AAS, Varian SpectrAA 10). The amount of free lead was determined using a method developed by Kruidhof and de Vries. ${ }^{13}$ This method implies extraction of the lead with a $0.1 M$ 8-hydroxyquinoline solution and subsequent AAS.

\section{Results}

Two compositions were prepared, $\mathrm{PbMg}_{0.3} \mathrm{Nb}_{0.6} \mathrm{Zr}_{0.1} \mathrm{O}_{3}$ (PMNZ/10) and $\mathrm{PbMg}_{0.32} \mathrm{Nb}_{0.65} \mathrm{Zr}_{0.03} \mathrm{O}_{3}$ (PMNZ/3). Slight

\footnotetext{
Manuscript No. 191016. Received May 7, 1997; approved June 17, 1997.

*Member, American Ceramic Society.

$+82 \%<\Delta C<+22 \%$ in a temperature range from $-30^{\circ}$ to $+85^{\circ} \mathrm{C}$
}

*erac, Milwaukee, WI delivered by Micropure, Driebergen, The Netherlands. Aldrich-Chemie GmbH and Co., Steinheim, Germany.

"E. Merck, Darmstadt, Germany. 


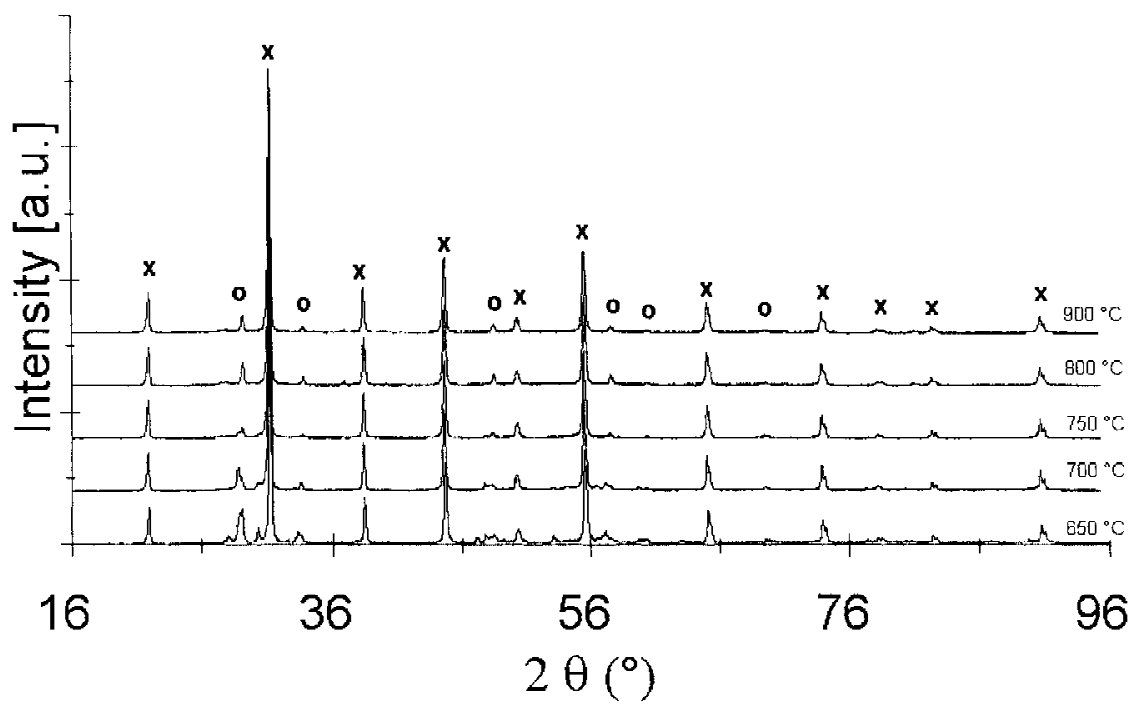

Fig. 1. XRD spectra of calcined PMNZ/3 powder calcined at different temperatures: $(x)$ the desired perovskite phase, and (o) the pyrochlore phase.

modifications of these compositions, with $5 \%$ more and $5 \%$ less lead oxide by weight, were prepared too. On the basis of XRD spectra of PMNZ/3, powders calcined at different temperatures, a calcination temperature of $700^{\circ} \mathrm{C}$ was chosen. Room-temperature XRD spectra as a function of calcination temperature are given in Fig. 1. As can be clearly seen from Fig. 1, above $750^{\circ} \mathrm{C}$ calcination temperature a pyrochlore second phase shows up. More information about the XRD spectrum of this composition can be found in Ref. 14. The influence of lead modifications on the PMNZ/3 compositions can be seen in Fig. 2. As can be seen from these XRD spectra, in the composition with $5 \%$ less lead oxide, there is a slight amount of second phase which is closely related to the pyrochlore phase described by Shrout and Swartz. ${ }^{11}$ The composition with $5 \%$ more lead oxide as well as the stoichiometric composition contain a slight amount of free lead oxide second phase (2.7 and 4.0 vol\%, respectively, as determined by the method described in Ref. 13).

A SEM picture (JEOL JSM-5800) of the calcined PMNZ/3 powder is given in Fig. 3. To determine the optimal sintering temperature, dilatometer (Netzsch 402E) curves of the compositions were measured. The dilatometer curves for the
PMNZ/3 and PMNZ/10 compositions including the lead modifications are given in Figs. 4 and 5, respectively. As can be seen from these dilatometer curves, the stoichiometric composition always has the highest final density. The PMNZ/10 compositions could not be sintered to greater than $84 \%$ relative density, whereas the PMNZ/3 stoichiometric composition did reach a final relative density of $95 \%$ at $900^{\circ} \mathrm{C}$.

A SEM picture of a sintered PMNZ/3 compact is given in Fig. 6. In this picture the arrows indicate the free lead oxide second phase as determined with the backscattered electron option on a JEOL JSM-35CF. This backscattered electron image is given in Fig. 7.

The dielectric constant $(\epsilon)$ as well as the loss tangent $(\tan \delta)$ of the stoichiometric PMNZ/3 material were measured in a temperature-controlled capacitance bridge (HP 4284A LCR meter) at $1 \mathrm{kHz}$ and $1.00 \mathrm{~V}$. Prior to the measurements the samples were machined to a diameter of $5 \mathrm{~mm}$ and a thickness of $0.5 \mathrm{~mm}$. On both sides of the samples $\mathrm{Cr} / \mathrm{Ni}-\mathrm{Au}$ electrodes with a diameter of $4.8-4.9 \mathrm{~mm}$ were evaporated. The results of these measurements as a function of the sintering temperature of the material are given in Table I. It is not clear why the material with a sintering temperature of $1000^{\circ} \mathrm{C}$ has a lower

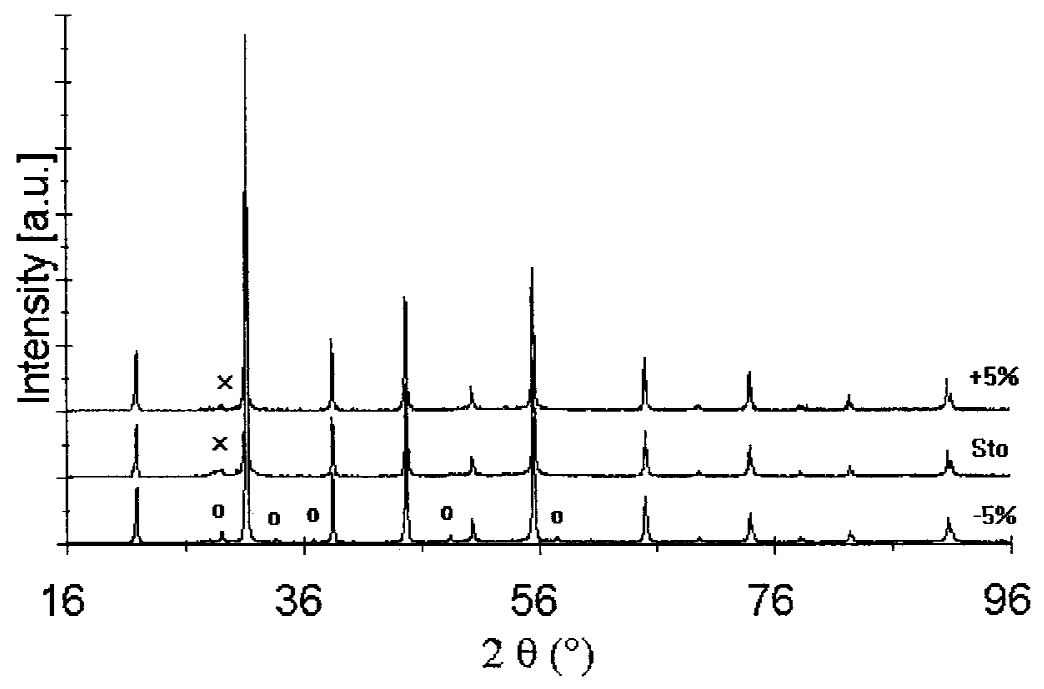

Fig. 2. XRD spectra of sintered PMNZ/3 samples (stoichiometric (Sto) and with 5\% more $(+5 \%)$ and $5 \%$ less $(-5 \%)$ lead oxide): $(\times)$ lead oxide, and (o) the pyrochlore phase. 


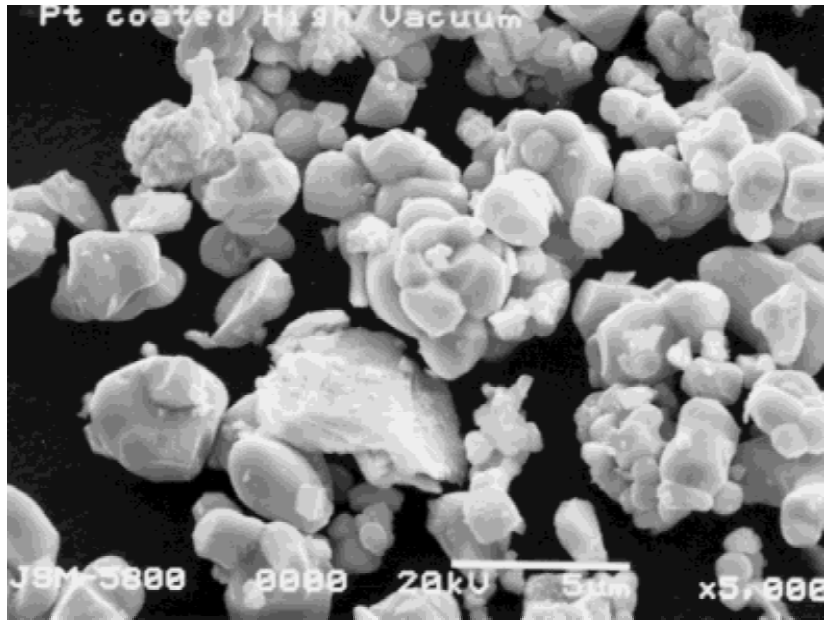

Fig. 3. Calcined powder of PMNZ/3.

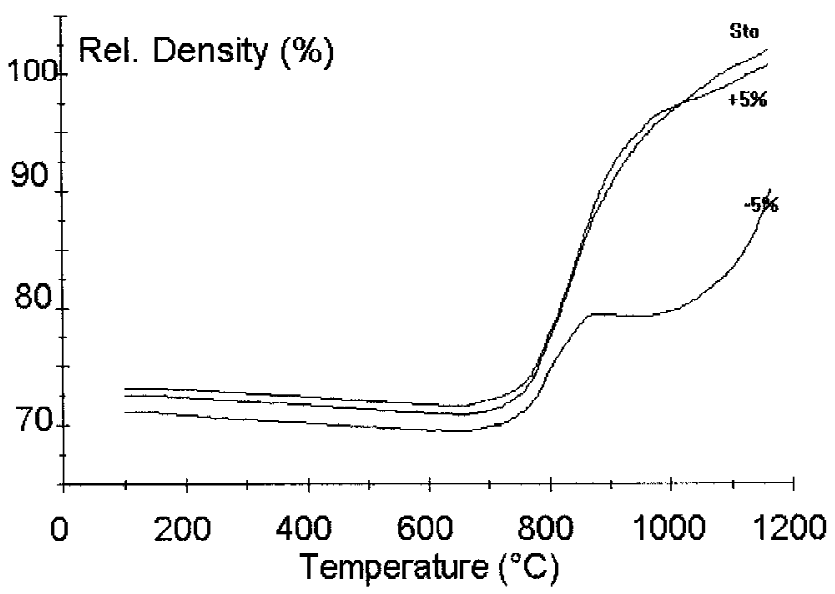

Fig. 4. Dilatometer curves of the three P0MNZ/3 compositions.

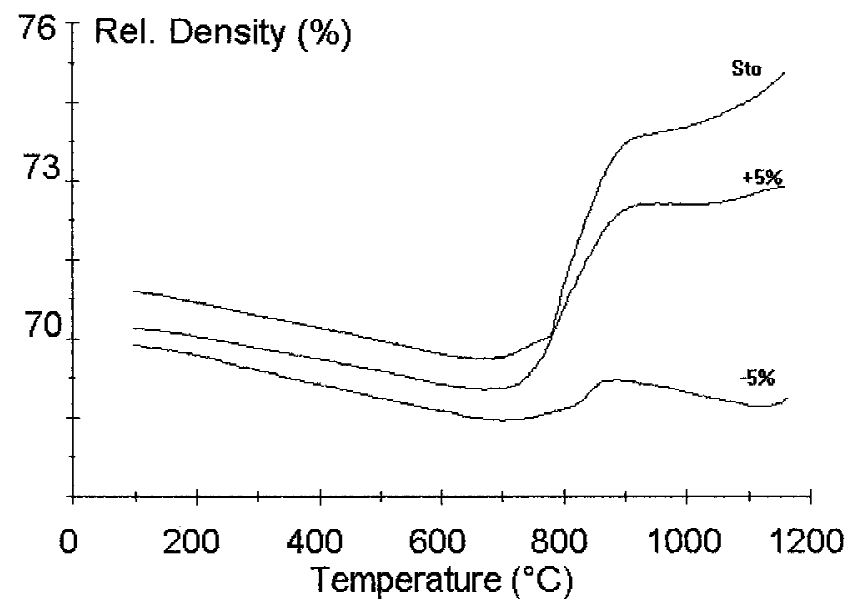

Fig. 5. Dilatometer at $900^{\circ} \mathrm{C}$. The arrows indicate the free lead oxide second phase.

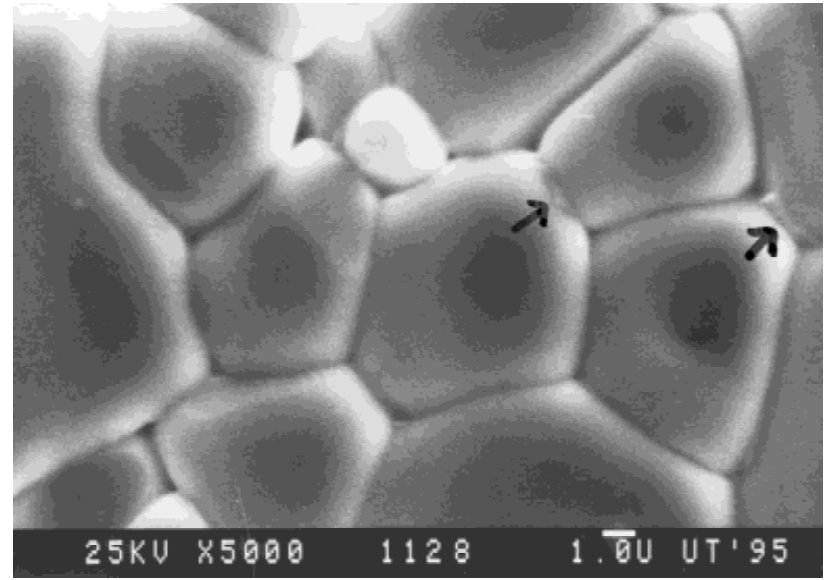

Fig. 6. Compact sintered at $900^{\circ} \mathrm{C}$. The arrows indicate the free lead oxide second phase.

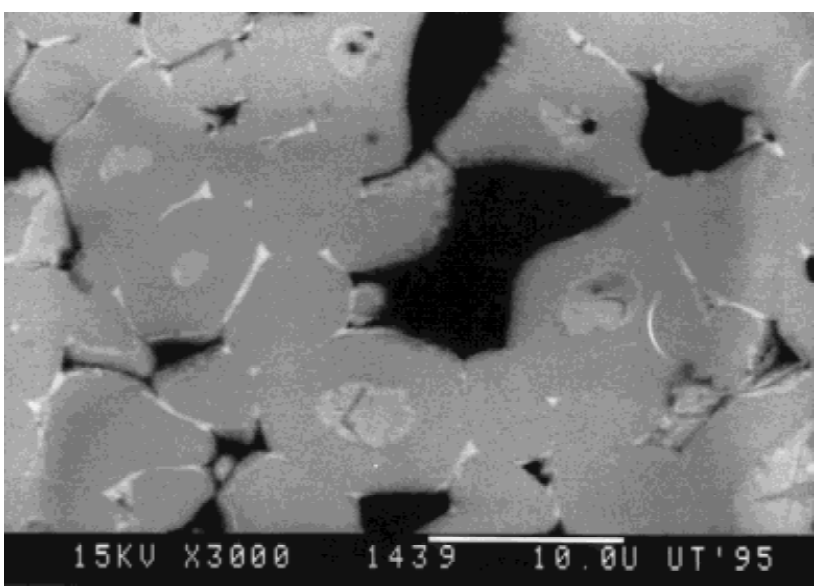

Fig. 7. Backscattered electron picture of $P M N Z / 3$. The light areas indicate the lead oxide second phase.

Table I. Dielectric Properties of PMNZ/3 Materials as a Function of the Sintering Temperature

\begin{tabular}{lcrrr}
\hline $\begin{array}{l}\text { Sintering } \\
\text { temp }\left({ }^{\circ} \mathrm{C}\right)\end{array}$ & $\epsilon_{\max }$ & $\epsilon\left(25^{\circ} \mathrm{C}\right)$ & $\tan \delta$ & $T_{\mathrm{C}}\left({ }^{\circ} \mathrm{C}\right)^{\dagger}$ \\
\hline 1000 & 11877 & 10254 & 0.0052 & 1.3 \\
950 & 11121 & 9262 & 0.0058 & 3.0 \\
900 & 11120 & 9290 & 0.0084 & 3.0 \\
850 & 10495 & 8849 & 0.0101 & 3.1 \\
\hline
\end{tabular}

Curie temperature than the other materials. A representative $\epsilon(T) / \tan \delta$ curve is given in Fig. 8. In this curve the EIA specifications $\mathrm{Y}^{\circ} \mathrm{U}^{\dagger \dagger}$ and $\mathrm{X} 7 \mathrm{R}^{\ddagger \ddagger}$ are indicated by lines. As can be seen from Fig. 8, the material meets Y5U specifications, but X7R specifications are not met.

dc-resistance measurements on PMNZ/3 samples with different sintering temperatures indicate that the specific resistances are of the order of $1 \times 10^{10} \Omega \cdot \mathrm{m}$ at $25^{\circ} \mathrm{C}$ and that the sintering temperature of the material has no significant effect on the resistance of that material. Accelerated life testing experiments by measurements of the dc resistance as a function of

\footnotetext{
$\$ 56 \%<\Delta C<22 \%$ in the temperature range from $-30^{\circ}$ to $+85^{\circ} \mathrm{C}$.

$15 \%<\Delta C<15 \%$ in the temperature range from $-55^{\circ}$ to $+125^{\circ} \mathrm{C}$.
} 


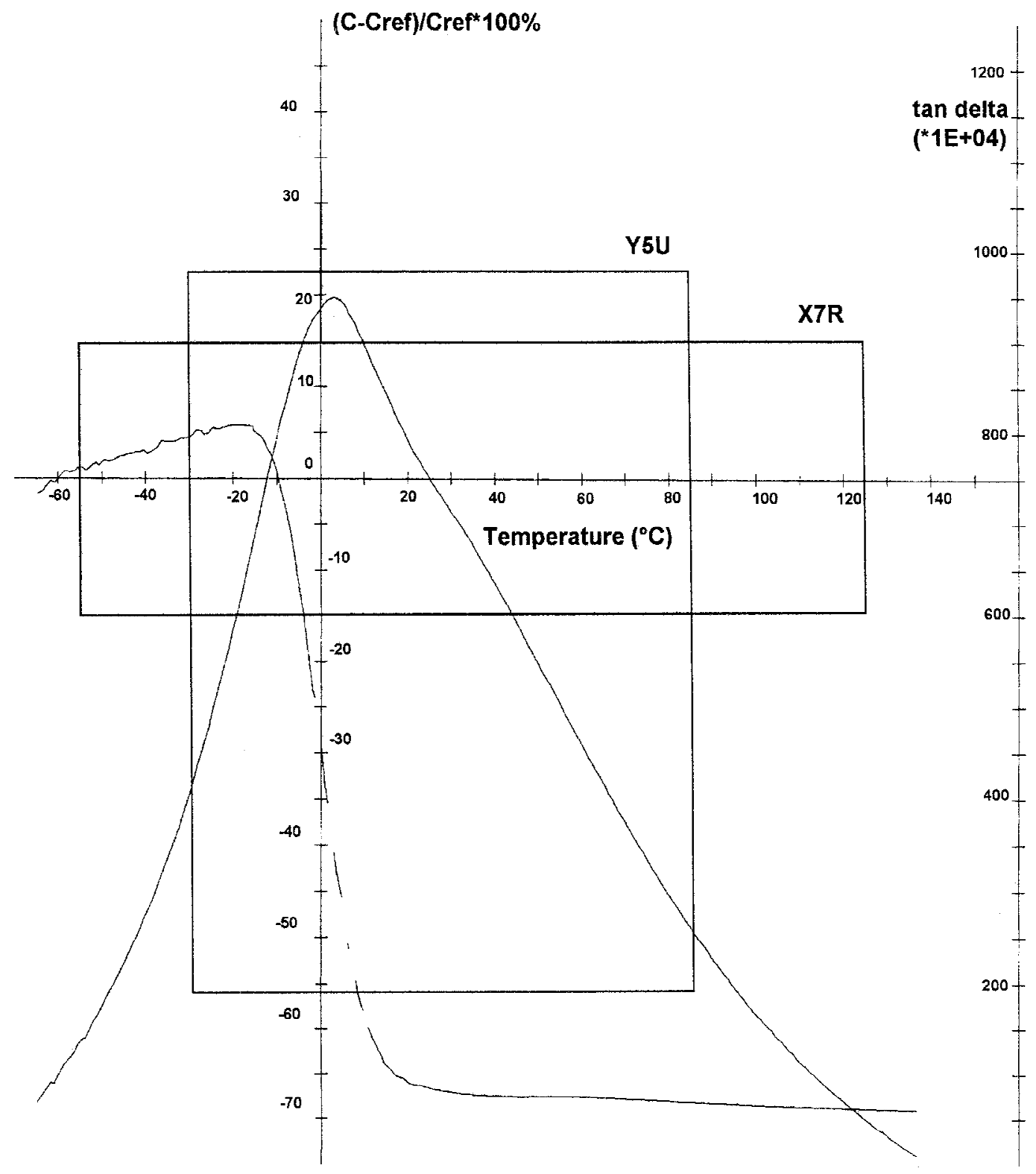

Fig. 8. Representative $\epsilon(T)$ and tan $\delta$ curve for PMNZ/3 material, showing X7R and Y5U specifications.

time at $200^{\circ} \mathrm{C}$ with $500 \mathrm{~V}$ applied were performed. No degradation of the properties of the material was observed for more than 3 weeks.

For the use of the material in capacitor applications also the fracture toughness of the material is of great importance too. Fracture toughness measurements were performed using the single edge notched beam (SENB) method. In this method a single notch with a known depth is made in the sample, after which the sample is cracked. The pressure needed for cracking the sample is recorded. From this pressure the fracture toughness can be calculated according to the following equation:

$$
K_{1 \mathrm{C}}=\frac{3 P s Y \sqrt{a}}{2 b^{2} w}
$$

In this equation, $P$ stands for the fracture load of the sample and $s, w, b$, and $a$ are the length, height, width, and notch depth (in meters) of the sample, respectively. $Y$ is a geometrical factor depending on loading conditions. (See Ref. 15 for further information concerning fracture toughness measurements.)

The measurements indicate a toughness of $2.0 \mathrm{MPa} \cdot \mathrm{m}^{-1 / 2}$ for the material, which is higher than the values given by de With ${ }^{15}$ for barium titanate used for CMCs $0.7-1.5 \mathrm{MPa}^{-1 / 2}$. This indicates that there will no problems in using these materials in the mounting equipment currently used in the electronics industry.

\section{Discussion and Conclusions}

It is possible to synthesize PMNZ/3 without any pyrochlore second phase at sintering temperatures as low as $900^{\circ} \mathrm{C}$ using the columbite synthesis route. After sintering, a slight lead oxide second phase was observed in the stoichiometric composition. PMNZ/10, however, could not be sintered dense. After an extra lead oxide addition of $5 \%$ by weight, the material had a density that was even lower than the stoichiometric composition.

The stoichiometric PMNZ/3 material seems to be an interesting material for use in MLCC applications with its high dielectric constant at room temperature (up to 10000 ) and its low sintering temperature of $900^{\circ} \mathrm{C}$. This enables the use of cheap silver-based electrodes. The material has a sufficiently low dielectric loss $(\tan \delta)$ and the relatively high fracture strength will not restrict future use in MLCC applications. The accelerated life testing too did not reveal any restrictions either.

The slight lead oxide second phase may be the cause of a 
somewhat lower dielectric constant than comparable materials in the literature, ${ }^{16}$ but the dielectric maximum is still rather high. Moreover, the curve of the dielectric constant against the temperature has a broad Curie region meeting even Y5U specifications of the EIA. The broadening of the Curie region might be enlarged by silver doping, as described by Mahler. ${ }^{9}$ Then even the X7R specifications might be met. Doping the material with extra lead oxide has proved not to be very useful for this material. The stoichiometric composition has the highest sintering density and excellent dielectric properties.

Acknowledgments: Drs. S. van der Gijp and Dr. A. J. A. Winnubst are gratefully acknowledged for fruitful discussions; Dipl. Ing. M. Schmidt performed the electric measurements.

\section{References}

${ }^{1}$ C. G. F. Stenger and A. J. Burggraaf, "Study of Phase Transitions and Properties of Tetragonal $(\mathrm{Pb}, \mathrm{La})(\mathrm{Zr}, \mathrm{Ti}) \mathrm{O}_{3}$ Ceramics. I. Phase Diagram and B-Phase," J. Phys. Chem. Solids, 41, 17-23 (1980).

${ }^{2}$ C. G. F. Stenger and A. J. Burggraaf, "Study of Phase Transitions and Properties of Tetragonal $(\mathrm{Pb}, \mathrm{La})(\mathrm{Zr}, \mathrm{Ti}) \mathrm{O}_{3}$ Ceramics. II. Diffuse Phase Transitions and Thermodynamics,"'J. Phys. Chem. Solids, 41, 25-30 (1980).

${ }^{3}$ C. G. F. Stenger and A. J. Burggraaf, "Study of Phase Transitions and Properties of Tetragonal $(\mathrm{Pb}, \mathrm{La})(\mathrm{Zr}, \mathrm{Ti}) \mathrm{O}_{3}$ Ceramics. III. Transition Induced by Electric Fields," J. Phys. Chem. Solids, 41, 31-41 (1980).

${ }^{4}$ T. R. Shrout and A. Halliyal, "Preparation of Lead-Based Ferroelectric Relaxors for Capacitors," Am. Ceram. Soc. Bull., 66, 704-11 (1987).
${ }^{5}$ A. Morell and J. C. Niepce, " $\mathrm{BaTiO}_{3}$-Based Materials for MLC Capacitors Applications,"' J. Mater. Educ., 13, 173-232 (1991).

${ }^{6} \mathrm{P}$. Ravindranathan, S. Komarneni, A. S. Bhalla, and R. Roy, "Synthesis and Dielectric Properties of Solution Sol-Gel Derived $0.9 \mathrm{~Pb}\left(\mathrm{Mg}_{1 / 3} \mathrm{Nb}_{2 / 3}\right) \mathrm{O}_{3}$. 0.1 $\mathrm{PbTiO}_{3}$ Ceramics," J. Am. Ceram. Soc. 74 [12] 2996-99 (1991).

${ }^{7}$ K. Katayama, M. Abe, T. Akiba, and H. Yanagida, "Sintering and Dielectric Properties of PMN-PT,', J. Eur. Ceram. Soc. 5, 183-91 (1993).

${ }^{8}$ G. A. Smolenskii and A. I. Agranovskaya, "Dielectric Polarization and Losses of Some Complex Compounds," Sov. Phys.-Tech. Phys. (Engl. Transl.), 1380-82 (1958).

${ }^{9}$ G. H. Mahler, "Effect of Silver Doping on the Physical and Electrical Properties of PLZT Ceramics,"' J. Am. Ceram. Soc., 66 [6] 408-13 (1983).

${ }^{10}$ Y. Sato, H. Kanai, and Y. Yamashita, "Effects of Silver and Palladium Doping on the Dielectric Properties of $0.9 \mathrm{~Pb}\left(\mathrm{Mg}_{1 / 3} \mathrm{Nb}_{2 / 3}\right) \mathrm{O}_{3} \cdot 0.1 \mathrm{PbTiO}_{3} \mathrm{Ce}-$ ramic," J. Am. Ceram. Soc., 79 [1] 261-65 (1996).

${ }^{11}$ T. R. Shrout and S. L. Swartz, "Dielectric Properties of Pyrochlore Lead Magnesium Niobate," Mater. Res. Bull. 18, 663-67 (1983).

${ }^{12}$ S. L. Swartz, T. R. Shrout, W. A. Schulze, and L. E. Cross, "Dielectric Properties of Lead-Magnesium Niobate Ceramics," J. Am. Ceram. Soc., 67 [5] 311-15 (1984).

${ }^{13} \mathrm{H}$. Kruidhof and K. de Vries, "The Determination of Small Amounts of Free Lead Oxide in Lead Compounds,"' Anal. Chim. Acta, 90, 301-302 (1977)

${ }^{14} \mathrm{~A}$. Nijmeijer, J. Boeijsma, and H. Kruidhof, "Powder Diffraction of $\mathrm{Pb}_{0.95} \mathrm{Mg}_{0.26} \mathrm{Nb}_{0.60} \mathrm{Zr}_{0.03} \mathrm{O}_{2.78}$," Powder Diffr., 11 [2] 85-87 (1996).

${ }^{15} \mathrm{G}$. de With, "Structural Integrety of Ceramic Multilayer Capacitor Materials and Ceramic Multilayer Capacitors," J. Eur. Ceram. Soc., 12, 323-36 (1993)

${ }^{16} \mathrm{M}$. Villegas, J. R. Jurado, C. Moure, and P. Duran, "Processing and Properties of $\mathrm{Pb}\left(\mathrm{Mg}_{1 / 3} \mathrm{Nb}_{2 / 3}\right)-\mathrm{PbZrO}_{3}-\mathrm{PbTiO}_{3}$ Ceramic Relaxors," J. Mater. Sci. 29, 1090-96 (1994). 